\title{
Effects of Carbon Content on the Diffusion Bonding of Iron and Steel to Titanium
}

\author{
Tadashi MOMONO, ine late Toshio ENJO1) and Kenji IKEUCHI1) \\ Department of Metallurgical Engineering, Muroran Institute of Technology, Mizumoto-chc: Muroran, Hokkaido, 050 Japan. \\ Research Institute, Osaka University, Mihogaoka, Ibaraki, Osaka-fu, 567 Japan.
}

1) Welding

(Received on February 5, 1990; accepted in the final form on June 29, 1990)

\begin{abstract}
A commercially pure titanium has been diffusion-bonded to iron and steels of various carbon contents: low carbon steel with $0.01 \% \mathrm{C}(\mathrm{ULC})$, mild steel with $0.19 \% \mathrm{C}$ (S20C) and spheroidal graphite cast iron with $3.75 \% \mathrm{C}$ (FCD). The tensile strength of joints bonded below $900^{\circ} \mathrm{C}$ was hardly influenced by the carbon content, and increased with the rise in bonding temperature. Above $900^{\circ} \mathrm{C}$ however, the strength of the ULC/Ti joint was almost independent of the bonding temperature, that of the $\mathrm{S} 20 \mathrm{C} / \mathrm{Ti}$ joint decreased with the rise in bonding temperature, and that of the $\mathrm{FCD} / \mathrm{Ti}$ increased. The interlayer forming along the bond interface consisted only of TiC in the $\mathrm{FCD} / \mathrm{Ti}$ joint and of $\mathrm{TiFe}$ and $\mathrm{TiFe}_{2}$ in the $\mathrm{ULC} / \mathrm{Ti}$. Since $\mathrm{Ti}$ and $\mathrm{Fe}$ diffused over much longer distances in the ULC/Ti than in the $\mathrm{FCD} / \mathrm{Ti}$, the TiC layer may be considered to interfere with the interdiffusion of $\mathrm{Ti}$ and $\mathrm{Fe}$, and consequently to suppress the formation of TiFe and $\mathrm{TiFe}_{2}$ which decrease the joint strength more seriously than $\mathrm{TiC}$. The interlayer in the $\mathrm{S} 20 \mathrm{C} / \mathrm{Ti}$ consisted of $\mathrm{TiC}$ as well as TiFe and $\mathrm{TiFe}_{2}$. The coexisting carbide and intermetallic compounds in the interlayer seems to have more detrimental effect on the joint strength than those formed individually.
\end{abstract}

KEY WORDS: diffusion bonding; composite metal; titanium; carbon steel; cast iron; intermetallic compound; joint strength; carbide; diffusion.

\section{Introduction}

With the recent developments of mass production technology of clad steels, their application to industries has been extended very widely, ranging from chemical plants to dam gates. ${ }^{1)}$ They are produced by various processes, such as hot rolling, ${ }^{2)}$ explosive bonding, ${ }^{3)}$ overlay welding, ${ }^{4,5)}$ enshrouding casting ${ }^{6)}$ and diffusion bonding. ${ }^{\text {7) }}$ The titanium clad steel, one of the most widely use clad steels, is produced by the hot rolling and explosive bonding processes.

Since brittle intermetallic compounds are formed in the binary system of iron and titanium, many investigation $s^{8-10)}$ have been reported of the effect of the intermetallic compound on the bond strength, including the application of the intermediate metal to preventing the formation of the intermetallic compound. For example, when steels of various carbon contents were bonded to a titanium by the hot rolling process without an intermediate metal, the shear strength of the joint scattered to a large extent, and so no systematic relation could be found between the strength and the bonding temperature. ${ }^{10)}$ On the other hand, Arata et al. ${ }^{11}$ reported that maximum joint strength could be obtained at bonding temperatures from 800 to $920^{\circ} \mathrm{C}$ in the diffusion bonding of a mild steel (JIS SS41) to a titanium, but Shimazaki et al. ${ }^{8)}$ reported that the joint strength increased with the rise in bonding temperature. In these studies, it was also suggested that the titanium carbide was formed at the bond interface through the reaction of titanium with carbon in the steel and exerted detrimental effects on the joint strength.

The significant discrepancy in the joint strength as mentioned above should be considered in connection with the difference in the kind and/or morphology of the intermetallic compound formed at the bond interface. The main purpose of the present investigation is, therefore, to make clear the relation between the joint strength and the formation of the intermetallic compound in the diffusion bonding ${ }^{12,13)}$ of titanium to iron-base alloys of various carbon contents with particular reference to the formation of titanium carbide.

\section{Experimental Procedures}

Chemical compositions of the base metals used are shown in Table 1. A low carbon steel (ULG), mild steel (S20C) and ferritic spheroidal graphite cast iron (FCD) were used as the iron-base metals, and commercially pure $\mathrm{Ti}$ (JIS TB35C) as the titanium base metal. The base metal was cut in a lathe to rod specimens $\phi 14 \times 20 \mathrm{~mm}$ for the diffusion bonding. One of the end faces of the specimen, the face to be bonded, was finished by grinding on \#240 emery paper, and subsequentry subjected to degrcasing with acetone and to wire-brushing (stainless steel wire 0.3 $\mathrm{mm}$ diameter and $20 \mathrm{~mm}$ long) just before the bonding.

The diffusion bonding was carried out in a vacuum of the order of $10^{-4}$ Torr using an apparatus as schematically shown in Fig. 1. A couple of specimens 
were set between the pressing axes of alumina rods, so that the brushing marks were crossed almost perpendicularly with each other. The bonding pressure, which was applied with a hydraulic press, was monitored with a small load cell. The set specimens were heated in a infrared image furnace at the heating rate of $1{ }^{\circ} \mathrm{C} / \mathrm{s}$, and the temperature of the specimens was kept at a desired bonding temperature to an accuracy of $\pm 1^{\circ} \mathrm{C}$. The temperature of the specimen was monitored with a CA thermocouple $(0.3 \mathrm{~mm}$ thick) percussion-welded to the specimen within $2 \mathrm{~mm}$ from the bond interface. The bonding pressure and time were fixed at $0.15 \mathrm{kgf} / \mathrm{mm}^{2}$ and $30 \mathrm{~min}$, respectively.

Joints obtained were machined to tensile test specimens in the form of bars with the gauge length of 15 $\mathrm{mm}$ and the gauge diameter of $7 \mathrm{~mm}$. The tensile test was carried out at the crosshead speed of 1.0 $\mathrm{mm} / \mathrm{min}$ at room temperature.

The intermetallic compound formed at the bond interface was identified by analyses of X-ray diffraction pattern from fractured surfaces of joints using $\mathrm{Cu}-\mathbf{K} \alpha$ radiation. Since all joints obtained were fractured in the close vicinity of or at the bond interface with rather flat fractured surfaces, the X-ray diffraction pattern may be consisted to indicate correctly the intermetallic compound formed at the bond interface.

Table 1. Chemical composition of base metals used. (wt\%)

\begin{tabular}{ccccccr} 
& $\mathrm{C}$ & $\mathrm{Si}$ & $\mathrm{Mn}$ & $\mathbf{P}$ & $\mathrm{S}$ & $\mathrm{Mg}$ \\
\hline ULC & 0.01 & 0.26 & 0.19 & 0.011 & 0.008 & - \\
$\mathrm{S} 20 \mathrm{C}$ & 0.19 & 0.07 & 0.72 & 0.026 & 0.026 & - \\
$\mathrm{FCD}$ & 3.75 & 3.00 & 0.13 & 0.038 & 0.010 & 0.042 \\
\hline \hline & $\mathrm{Fe}$ & $\mathrm{N}$ & $\mathrm{O}$ & $\mathrm{H}$ \\
\hline $\mathrm{Ti}$ & 0.12 & 0.0065 & 0.126 & 0.0035 \\
\hline
\end{tabular}

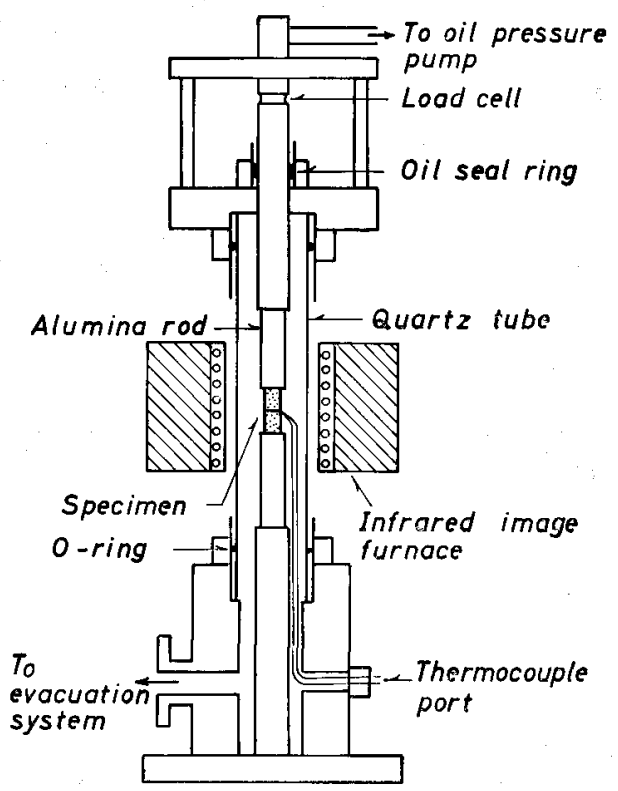

Fig. 1.

Schematic drawing of diffusion bonding apparatus.

\section{Experimental Results}

\subsection{Diffusion Bonding of FCD to $\mathrm{Ti}$}

Microstructures of $\mathrm{FCD} / \mathrm{Ti}$ joints bonded at 800 and $1000^{\circ} \mathrm{C}$ are shown in Figs. 2(a) and 2(b), respectively. No interlayer could be found at bonding temperatures $T_{i}$ below $800^{\circ} \mathrm{C}$ by the optical microstructure, while a interlayer $4-5 \mu \mathrm{m}$ thick was observed at $T_{B}$ of $1000^{\circ} \mathrm{C}$. X-ray diffraction patterns from fractured surfaces after the tensile test are shown in Fig. 3. As shown in Fig. 3, on the fractured surface of the FGD side, no diffraction line from intermetallic compounds of Fe-Ti binary system could be found, but those from $\mathrm{TiC}$ were observed in addition to those from $\alpha$-Fe base metals. On the Ti side, more intensive diffraction lines from $\mathrm{TiC}$ were observed than those on the FCD side. The fact that the diffraction line from $\mathrm{TiC}$ was observed on both sides suggests that the joint fractured in the $\mathrm{TiC}$ layer and/or at the

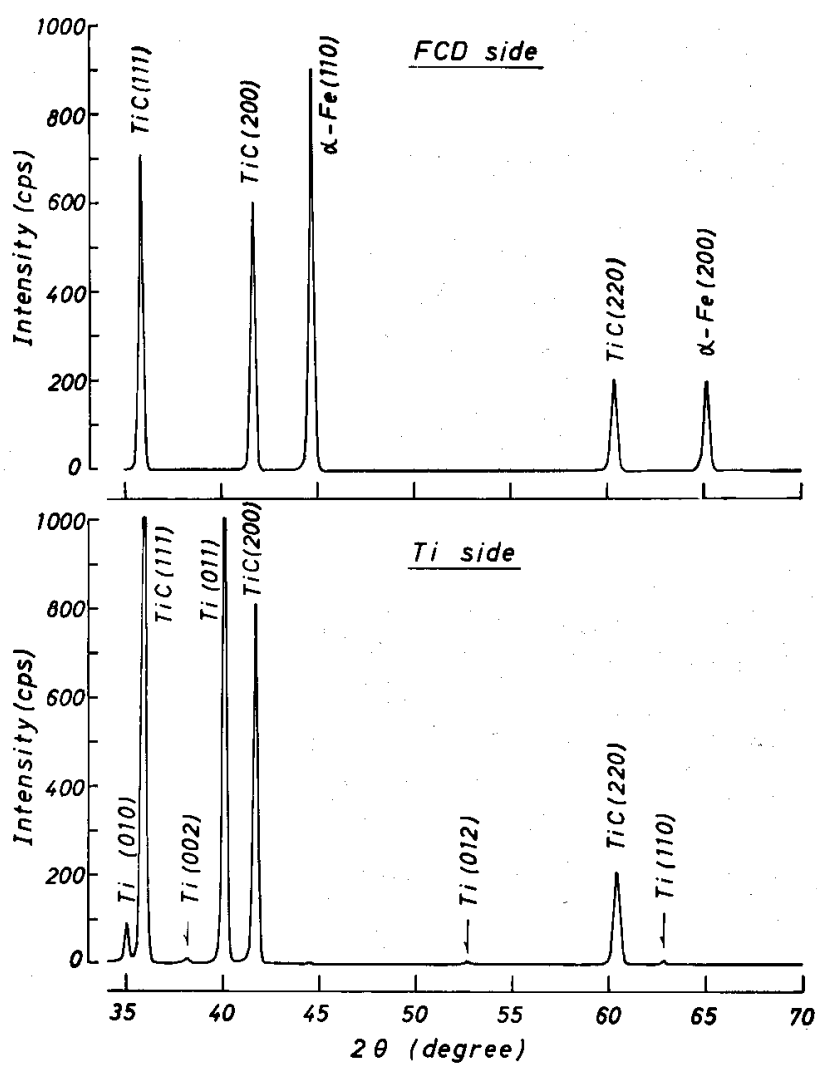

Fig. 3. X-ray diffraction patterns from fractured surfaces of a $\mathrm{FCD} / \mathrm{Ti}$ joint bonded at $1000^{\circ} \mathrm{G}$.

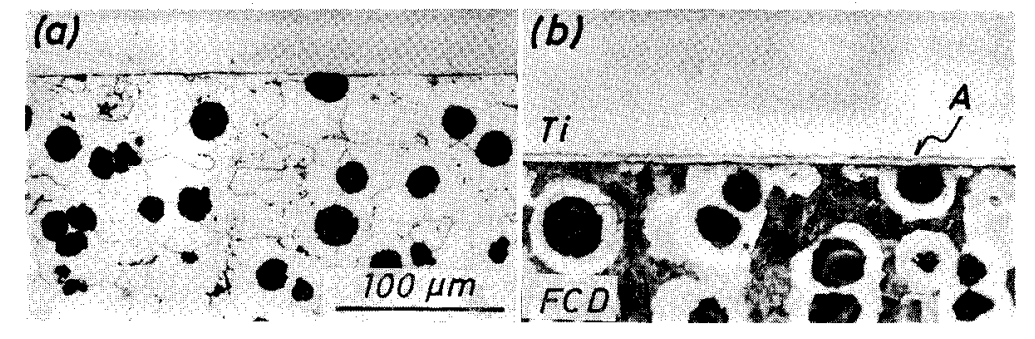

(a) Bonding temperature $T_{B}=800^{\circ} \mathrm{C}$

(b) $T_{B}=1000^{\circ} \mathrm{C}$

Fig. 2. Microstructures of FCD/Ti joints. 
interfaces between TiC and base metals. Since the intensity of the diffraction lines from $\mathrm{TiC}$ was higher on the $\mathrm{Ti}$ side, the bond strength of the $\mathrm{Ti} / \mathrm{TiC}$ interface was probably higher than that of the FCD/Ti interface.

In order to investigate the dependence of the thickness of $\mathrm{TiC}$ layer on the bonding temperature, the intensity of the diffraction line from $\mathrm{TiC}\{111\}$ plane is plotted against the bonding temperature in Fig. 4. The intensity of the diffraction line increased with the rise in bonding temperature, suggesting that the $\mathrm{TiC}$ layer became thicker with the rise in bonding temperature.

Distributions of $\mathrm{Fe}, \mathrm{Ti}$ and $\mathrm{C}$ in a $\mathrm{FGD} / \mathrm{Ti}$ joint bonded at $1000^{\circ} \mathrm{C}$ were analyzed by EPMA as shown in Fig. 5. The distribution curve of carbon had a peak at the bond interface, suggesting that $\mathrm{TiC}$ was formed in the interlayer as shown in Fig. 2(b). The amounts of $\mathrm{Ti}$ diffusing into FCD and of Fe diffusing into $\mathrm{Ti}$ were much smaller than those in a ULC/Ti

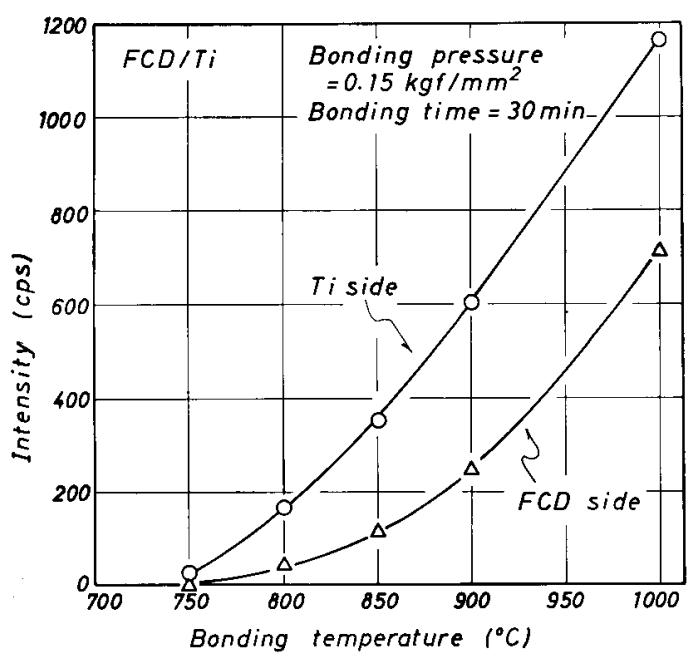

Fig. 4. Effect of bonding temperature on the peak height of $\{111\}-\mathrm{TiC}$ diffraction line from fractured surfaces of FCD/Ti joints.

\section{Graphite}

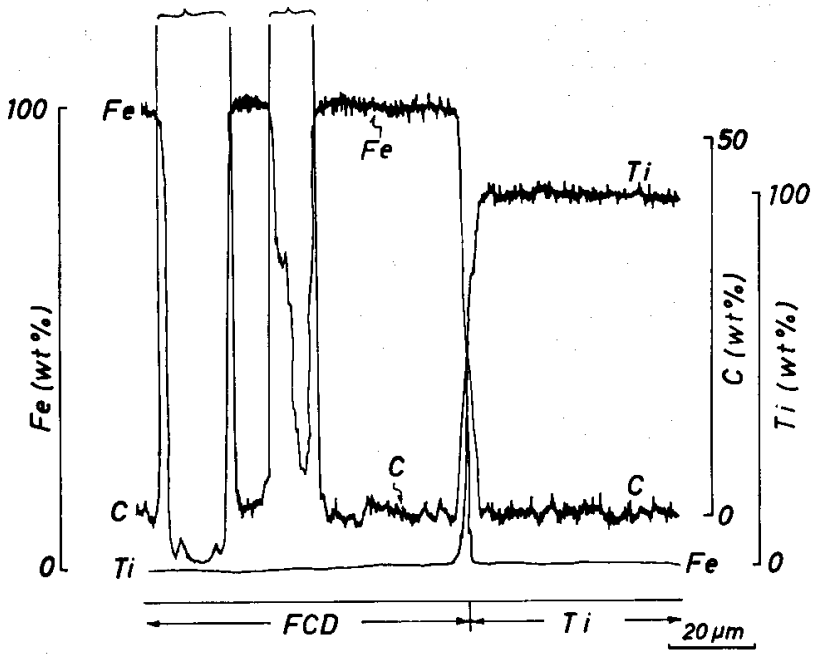

Fig. 5. EPMA line-scanning profiles across the bonding interface of a $\mathrm{FCD} / \mathrm{Ti}$ joint bonded at $1000^{\circ} \mathrm{C}$. joint bonded under the same conditions (see Fig. 7). These results suggest that the interdiffusion of $\mathrm{Ti}$ and Fe during the diffusion bonding was interfered by the presence of the $\mathrm{TiC}$ layer. The effects of bonding temperature on the tensile strength of $\mathrm{FCD} / \mathrm{Ti}$ joints are shown in Fig. 6. Though all the joints tested were fractured in the close vicinity of or at the bond interface, their strength increased with the rise in bonding temperature. Thus, the increase in the thickness of the $\mathrm{TiC}$ layer did not decrease the joint strength at bonding temperatures below $1000^{\circ} \mathrm{C}$. However, the increase in the joint strength tends to be saturated at bonding temperatures above $900^{\circ} \mathrm{C}$. This suggests that the tensile strength of $\mathrm{FCD} / \mathrm{Ti}$ joints was influenced by the gworth of the $\mathrm{TiC}$ layer and that it would be rather difficult to obtain bond strength not less than the strength of the base metal by increasing the boning temperature.

Though the FCD used contained $3.0 \% \mathrm{Si}$, it was not observed that $\mathrm{Si}$ had any significant effects on the formations of $\mathrm{TiC}$ or intermetallic compounds of $\mathrm{Ti}-$ Si system.

\subsection{Diffusion Bonding of $U L C$ to $\mathrm{Ti}$}

Microstructures of ULC/Ti joints bonded at 800 , 900 and $1000^{\circ} \mathrm{C}$ are shown in Figs. 7(a), 7(b) and 7 (c), respectively. No intermetallic compound layer could be recognized at the bonding temperature of $800^{\circ} \mathrm{C}$. As shown in Figs. 7(b) and 7(c), however, an interlayer and remarkable change in the microstructure of $\mathrm{Ti}$ adjacent to the bond interface were observed at the bonding temperatures of 900 and $1000^{\circ} \mathrm{C}$, i.e., above $\alpha \rightleftarrows \beta$ transformation temperature of Ti. That is, in Fig. 7(c), the dark thin layer just next to the bond interface indicated by the arrow ' $\mathrm{C}$ ' is regarded as the interlayer consisting of intermetallic compounds. The white non-etched region indicated by ' $\mathrm{D}$ ' is the $\beta$-Ti phase formed by the diffusion of $\mathrm{Fe}$ into $\mathrm{Ti}$, as can be seen from the results of X-ray diffraction analysis and EPMA described later (see Figs. 8 and 9). This $\beta$-Ti region was much harder than the Ti base metal; i.e., the Vicker's hard-

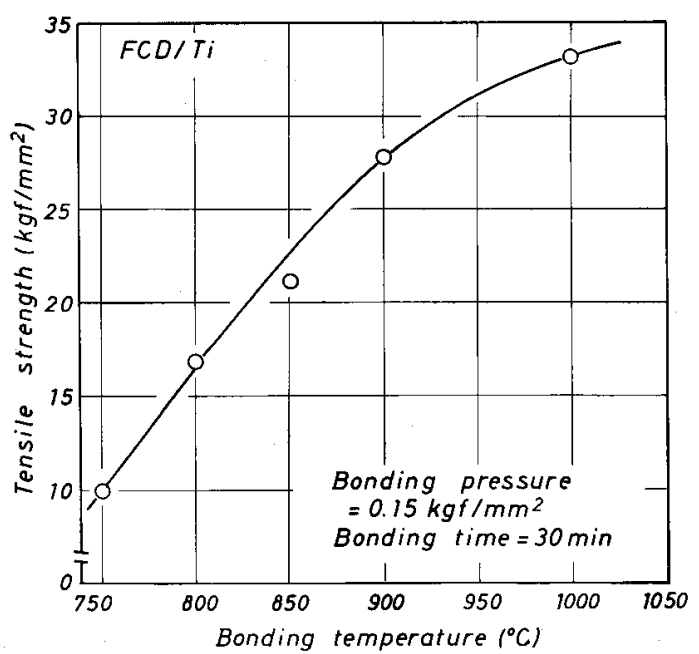

Fig. 6. Tensile strength of $\mathrm{FCD} / \mathrm{Ti}$ joints as a function of bonding temperature. 


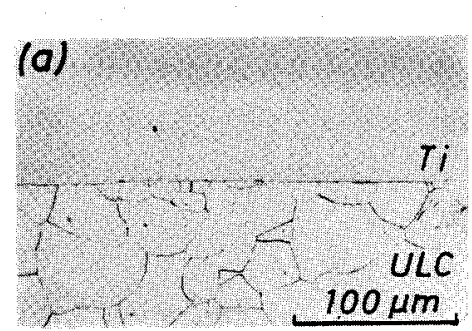

(a) $T_{B}=800^{\circ} \mathrm{C}$

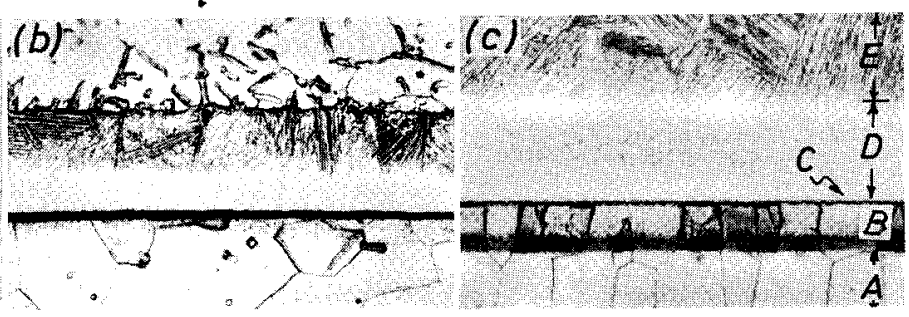

(b) $T_{B}=900^{\circ} \mathrm{C}$

(c) $T_{B}=1000^{\circ} \mathrm{C}$

Fig. 7. Microstructures of ULC/Ti joints.

ness number of the $\beta$-Ti region, which decreased with the increase in the distance from the bond interface, ranged from 463 to 365 as compared to that of the Ti base metal $\sim 170$. Region ' $\mathrm{E}$ ', showing Widmanstätten's structure, was formed as a result of $\alpha \rightarrow \beta$ transformation during the cooling process after the bonding. As shown in Figs. 7 (b) and $7(\mathrm{c})$, the width of these phases increased with the bonding temperature. This is consistent with the result reported by Shimazaki et al. ${ }^{8)}$ that the width of white layer incrcased with the bonding temperature.

$\mathrm{X}$-ray diffraction patterns from fractured surfaces of a joint bonded at $1000^{\circ} \mathrm{C}$ are shown in Fig. 8. On the fractured surface of the ULC side, diffraction lines from $\mathrm{TiFe}_{2}$, TiFe, $\alpha-\mathrm{Ti}$ and $\beta-\mathrm{Ti}$ were observed in addition to those from $\alpha-\mathrm{Fe}$, but those from $\mathrm{TiC}$ could not be detected. On the fractured surface of $\mathrm{Ti}$ side, strong diffraction lines from $\mathrm{TiFe}$ and rather weak diffraction lines from $\mathrm{TiFe}_{2}$ were observed in addition to those from $\alpha$-Ti and $\beta$-Ti. These results indicate that the interlayer shown in Fig. 7 (c) consisted of $\mathrm{TiFe}$ and $\mathrm{TiFe}_{2}$. Since diffraction lines from $\mathrm{TiFe}, \mathrm{TiFe}_{2}$ and $\beta$-Ti could be observed on the fractured surfaces of both ULC side and Ti side, the crack was probably propagated through the intermetallic compound layer and partially the $\beta$-Ti region. This suggests that the strength of this joint is controlled by the strength of the interlayer consisting of $\mathrm{TiFe}$ and $\mathrm{TiFe}_{2}$ and that of the $\beta$-Ti region.

In order to assign the phases identified by the $\mathrm{X}$ ray diffraction analysis to the microstructures shown in Fig. 7(c), the distribution of $\mathrm{Fe}, \mathrm{Ti}$ and $\mathrm{G}$ was investigated with EPM analysis. As shown in Fig. 9 , considerable amounts of $\mathrm{Fe}$ diffused into $\mathrm{Ti}$ base metal, while no detectable change in $\mathrm{C}$ content could be observed. Region 'D', where a significant increase in Fe content due to the diffusion was observed, can be assigned to $\beta-\mathrm{Ti}$, considering that $\mathrm{Fe}$ is an element stabilizing $\beta$-Ti. The amount of Ti diffusing into ULC was rather small, though a small increase in $\mathrm{Ti}$ content was observed in region ' B'. Since $\alpha$ Fe containing $2-7 \% \mathrm{Ti}$ is in equilibrium with $\mathrm{TiFe}_{2}$ at $\left.1000^{\circ} \mathrm{C},{ }^{14}\right)$ region ' $\mathrm{B}$ ' in Fig. $7(\mathrm{c})$ may be regarded as the $\alpha$-Fe. The interlayer ' $\mathrm{C}$ ' probably consisted of $\mathrm{TiFe}$ and $\mathrm{TiFe}_{2}$, though it was too thin to detect with EPMA.

The relation between tensile strength of the joint and bonding temperature is shown in Fig. 10. The tensile strength increased with the rise in bonding temperature up to about $900^{\circ} \mathrm{C}$, and became almost

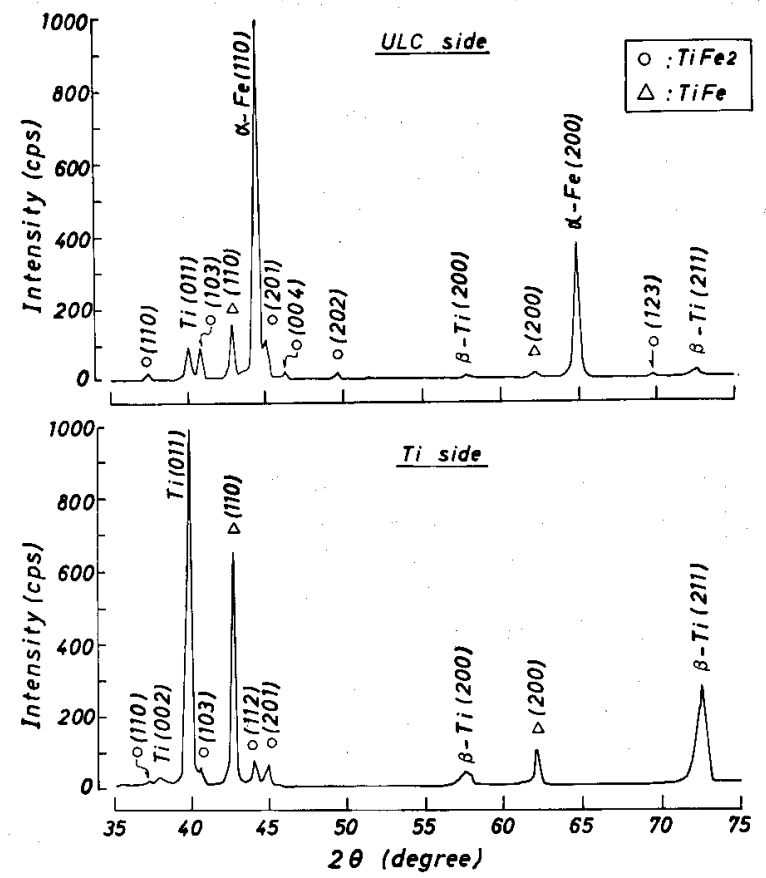

Fig. 8. X-ray diffraction patterns from fractured surfaces of a ULC/Ti joint bonded at $1000^{\circ} \mathrm{C}$.

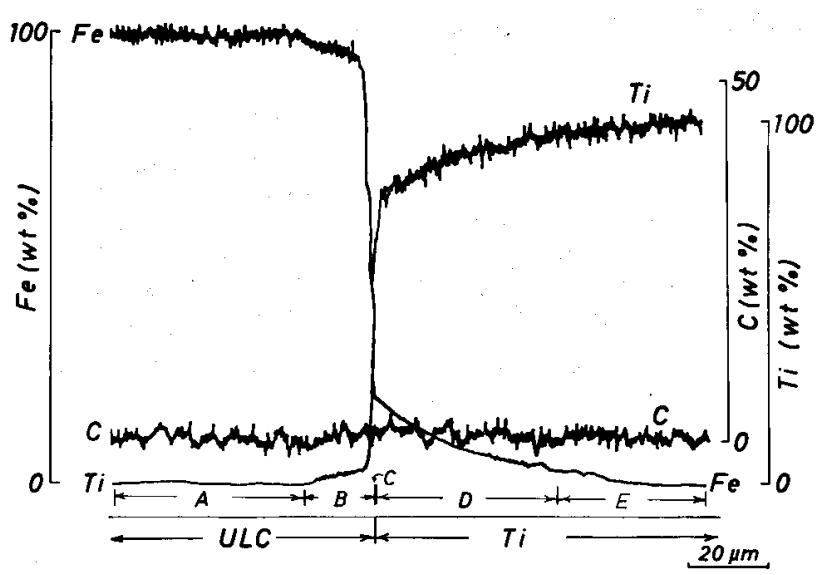

Fig. 9. EPMA line-scanning profiles across the bonding interface of a ULG/Ti joint bonded at $1000^{\circ} \mathrm{C}$. Symbols A-E correspond to those in Fig. 7(c).

constant above $900^{\circ} \mathrm{C}$. Since $\mathrm{TiFe}$ and $\mathrm{TiFe}_{2}$ were observed on the fractured surfaces of both Ti side and ULG side, it can be accounted for by the growth of these intermetallic compound layers that the tensile strength of joint did not increased with the rise in bonding temperature above $900^{\circ} \mathrm{C}$. This means that the tensile strength of joint bonded at temperatures 
above $900^{\circ} \mathrm{C}$ is controlled mainly by the strength of the intermetallic compound layers. The layers of TiFe and $\mathrm{TiFe}_{2}$ seems to have more detrimental effect on the joint strength than $\mathrm{TiC}_{1}$, since the tensile strength of the FCD/Ti joint in which only $\mathrm{TiC}$ was formed increased with bonding temperature even above $900^{\circ} \mathrm{C}$ as shown in Fig. 6. The increase in the joint strength with bonding temperature below $900^{\circ} \mathrm{C}$ can be accounted for by the decrease in the unbonded area, ${ }^{15)}$ since SEM observation of the fractured surface of joints showed that unbonded area characterized by the wire-brushing mark decreased with the rise in bonding temperature.

\subsection{Diffusion Bonding of $S 20 C$ to $\mathrm{Ti}$}

Microstructures of $\mathrm{S} 20 \mathrm{C} / \mathrm{Ti}$ joints bonded at 880 and $1000^{\circ} \mathrm{C}$ are shown in Figs. 11 (a) and $11(\mathrm{~b})$, respectively. At the bonding temperature of $880^{\circ} \mathrm{C}$, a discontinuous dark layer, which probably consisted of TiC, was observed at the bond interface. A decarburized band characterized by the disappearance of pearlite structure was also observed in the S20C adjacent to the bond interface. At the bonding temperature of $1000^{\circ} \mathrm{C}$, the decarburized band became wider, and a remarkable difference in the width of reaction or diffusion zone was observed over the whole bond interface. That is, the bond zone consisted of two characteristic places; the place where regions similar to ' $\mathrm{B}$ ' and ' $\mathrm{D}$ ' in the ULC/Ti joint were formed and the place where $\mathrm{T}_{\mathrm{i}}$ adjacent to the bond interface showed Widmanstätten's structure and region ' $\mathrm{B}$ ' was not observed.

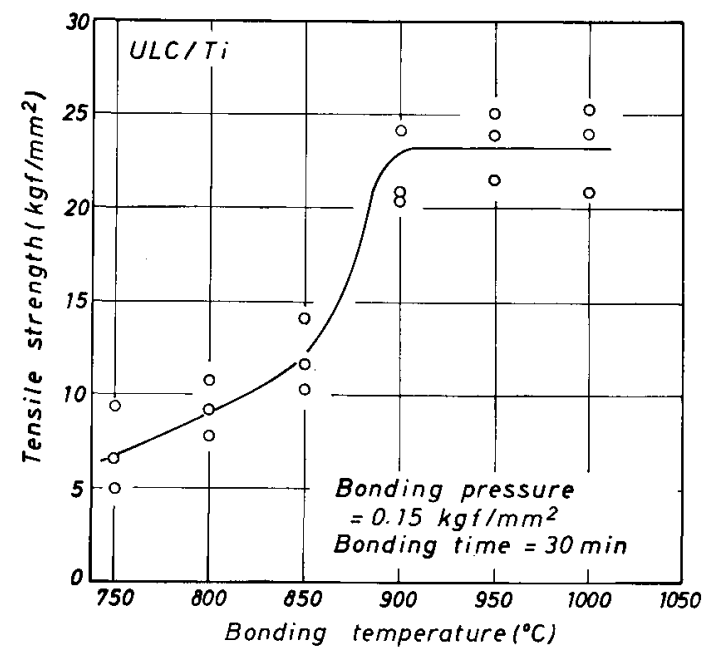

Fig. 10. Tensile strength of ULC/Ti joints as a function of bonding temperature.
$\mathrm{X}$-ray diffraction patterns from the fractured surfaces of a joint bonded at $1000^{\circ} \mathrm{C}$ are shown in Fig. 12. As shown in Fig. 12, diffraction lines from $\mathbf{T i C}$, $\mathrm{TiFe}_{2}$ and TiFe were observed on the S20C side, and diffraction lines from $\mathrm{TiC}$ and $\mathrm{TiFe}$ on the $\mathrm{Ti}$ side. These results, combined with those of the observation of microstructure, suggest that $\mathrm{TiFe}$ and $\mathrm{TiFe}_{2}$ were formed at the place having region ' $\mathrm{B}$ ' and ' $\mathrm{D}$ ' similar to those of the ULC/Ti joint and $\mathrm{TiC}$ was formed at the place without region ' $\mathrm{B}$ ' or ' $\mathrm{D}$ '. In fact, the distributions of $\mathrm{Fe}, \mathrm{Ti}$ and $\mathrm{G}$ analyzed with EPMA were almost the same as those of FCD/Ti joint shown in Fig. 5 at the place where $\mathrm{TiC}$ was formed, and almost the same as those of the ULC/Ti joint shown in Fig. 9 at the place where intermetallic compounds $\mathrm{TiFe}$ and $\mathrm{TiFe}_{2}$ were formed. That is, at the place where the $\mathrm{TiC}$ was formed, the interdiffusion of $\mathrm{Ti}$ and $\mathrm{Fe}$ was much suppressed as compared with the place where $\mathrm{TiFe}$ and $\mathrm{TiFe}_{2}$ were formed. This result also supports that the $\mathrm{TiC}$ layer acts as a barrier against the interdiffusion of $\mathrm{Ti}$ and Fe. At bonding temperatures below $900^{\circ} \mathrm{C}$, X-ray diffraction lines observed were only those from $\mathrm{TiC}$ except for $\alpha$-Fe and $\alpha$-Ti.

The relation between tensile strength of joints and bonding temperature is shown in Fig. 13. The tensile
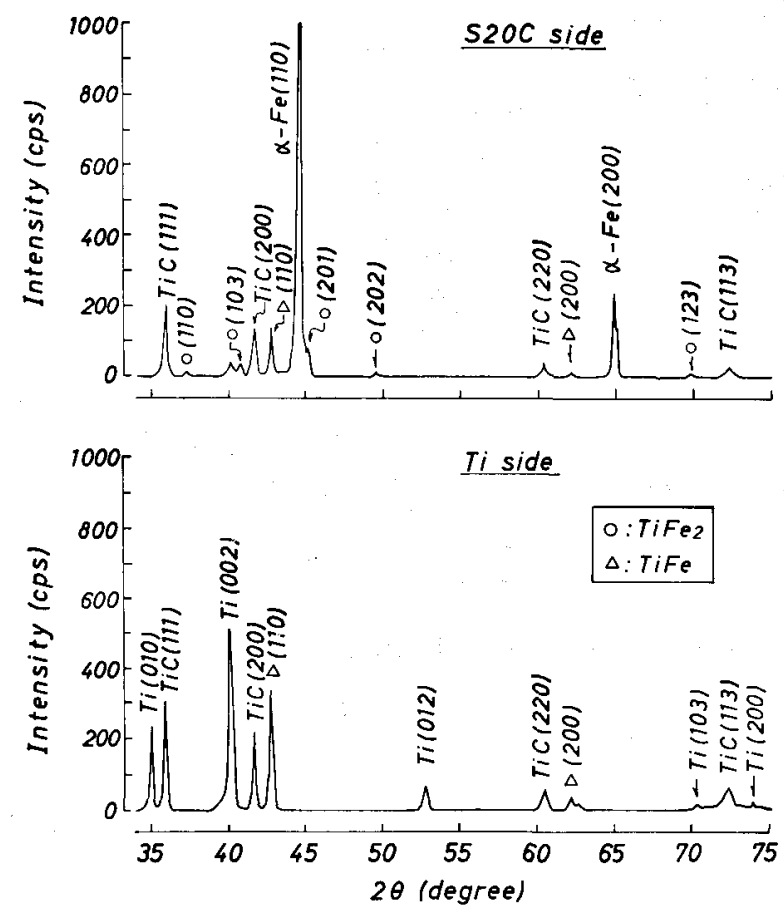

Fig. 12. X-ray diffraction patterns from fractured surfaces of a $\mathrm{S} 20 \mathrm{C} / \mathrm{Ti}$ joint bonded at $1000^{\circ} \mathrm{C}$.

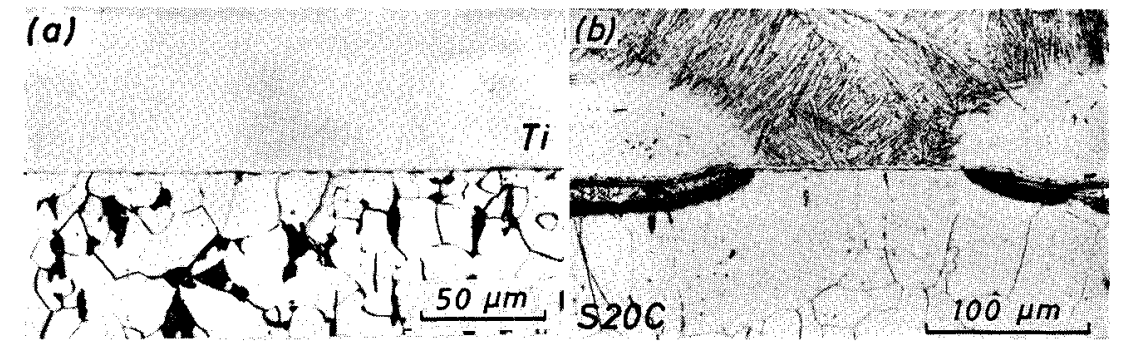

(a) $T_{B}=880^{\circ} \mathrm{C}$

(b) $T_{B}=1000^{\circ} \mathrm{C}$

Fig. 11.

Microstructures of S20G/Ti joints. 


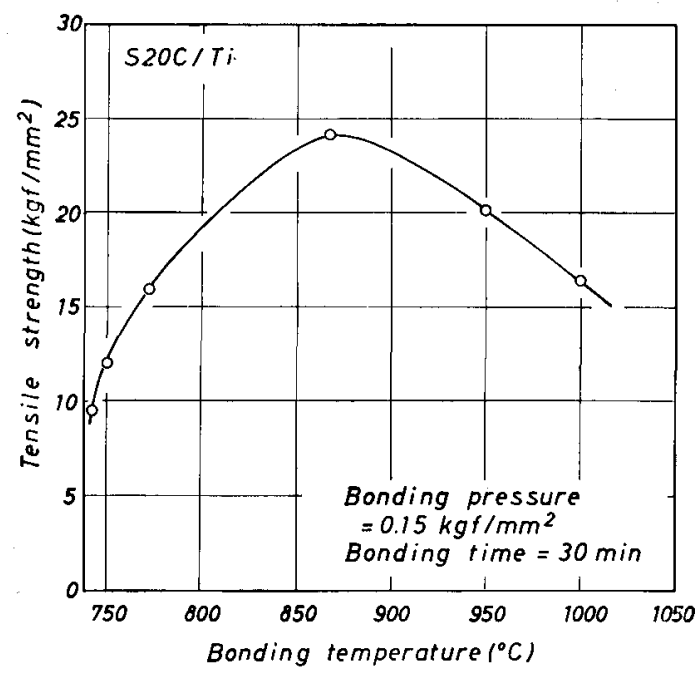

Fig. 13. Tensile strength of $\mathrm{S} 20 \mathrm{C} / \mathrm{Ti}$ joints as a function of bonding tempcraturc.

strength of joints increased with temperature below $870^{\circ} \mathrm{C}$ similarly to that of FCD/Ti joints, but above $870^{\circ} \mathrm{C}$ decreased with the rise in bonding temperature. That is, the tensile strength of the S20C/Ti joint decreased with the rise in bonding temperature when the interlayer of $\mathrm{TiG}_{\mathrm{G}}$ and the interlayer of $\mathrm{TiFe}$ and $\mathrm{TiFe}_{2}$ coexisted at the bond interface. This fact suggests that the $\mathrm{TiFe}$ and $\mathrm{TiFe}_{2}$ interlayer coexisting with the TiC interlayer had more detrimental effect on the joint strength than that in the ULC/Ti joint.

\section{Discussion}

As described above, the microstructure of the diffusion-bonded joint of iron-base alloys to titanium is influenced strongly by the carbon content; i.e., only the TiG layer was formed in the FGD/Ti joint, the intermetallic compounds layer of $\mathrm{TiFe}$ and $\mathrm{TiFe}_{2}$ was formed in the ULG/Ti joint, and both the $\mathrm{TiC}$ layer and the intermetallic compound layer were formed in the S20C/Ti joint. In order to discuss the formation of such compounds, the standard free energy changes due to the formation of $\mathrm{TiC}, \mathrm{TiFe}$ and $\mathrm{TiFe}_{2}$ are shown in Fig. 14. ${ }^{16,17)}$ The standard free energy change due to the formation of $\mathrm{TiC}$ was lowest of all the compounds of $\mathrm{TiFe}, \mathrm{TiFe}_{2}$ and $\mathrm{TiC}$. Therefore, $\mathrm{TiC}$ is perferentially formed at the bond interface of the FGD/Ti joint, in which the amount of $\mathrm{G}$ enough to form $\mathrm{TiC}$ is supplied from the FCD base metal. As mentioned in Sec. 3.1, the $\mathrm{TiC}$ layer acted as a barrier against the interdiffusion of $\mathrm{Ti}$ and $\mathrm{Fe}$ across the bond interface, and made it difficult to form the intermetallic compounds of $\mathrm{Ti}-\mathrm{Fe}$ binary system. For this reason, the intermetallic compound layer of ' $\mathrm{C} i-$ $\mathrm{Fe}$ binary system or $\beta$-Ti layer was not observed in the FGD/Ti joint.

While $\mathrm{TiC}$ has a simple crystal structure of $\mathrm{NaCl}$ (A15) type, ${ }^{19)} \mathrm{TiFe}_{2}$ and $\mathrm{TiFe}$ have rather complicated ones; $\mathrm{TiFe}_{2}$ is $\mathrm{MgZn}_{2}$ (G14) and $\mathrm{TiFe}$ is $\mathrm{BGG}$ (A2) or CsCl (B2). Especially, $\mathrm{TiFe}_{2}$ is known as the Laves phase, which is very hard and brittle. ${ }^{18}$ In view of the crystal structures and mechanical prop-

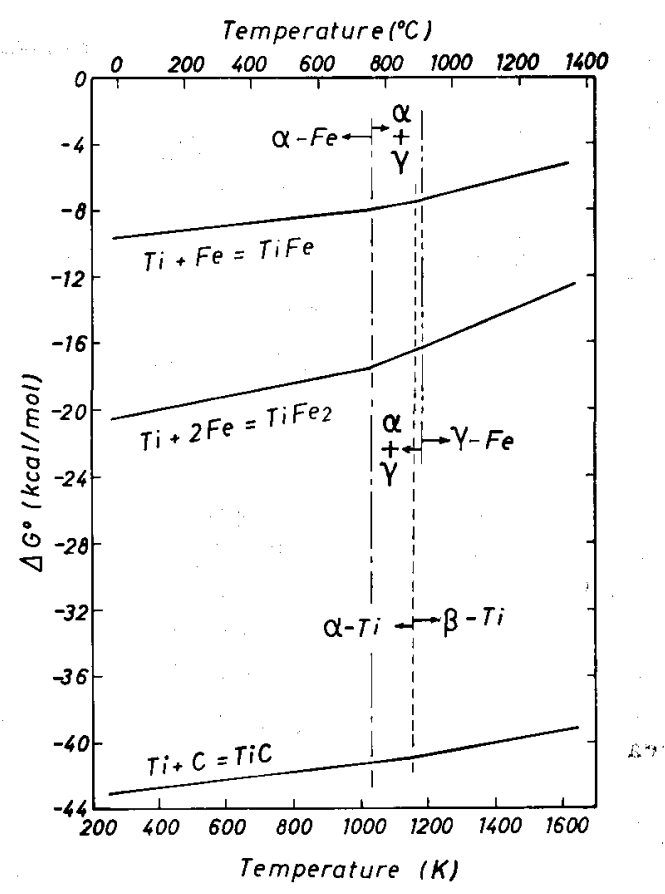

Fig. 14. Standard free energy change, $\Delta G^{\circ}$ of $\mathrm{TiC}, \mathrm{TiFe}_{2}$ and $\mathrm{TiFe}$ as a function of temperature.

erties of these phases, it seems likely that $\mathrm{TiC}$ is not so brittle as $\mathrm{TiFe}$ or $\mathrm{TiFe}_{2}$. For this reason, the tensile strength of the $\mathrm{FCD} / \mathrm{Ti}$ joint, in which only the $\mathrm{TiC}$ layer was formed, was higher than that of the ULC/Ti joint and the S20G/Ti joint.

It is said that the interlayer consisting of a brittle phase has detrimental effects on the mechanical properties of the joint when its thickness exceeds a critical value. ${ }^{19)}$ For instance, the strength of a joint between iron and titanium decreases abruptly if the thickness of the layer exceeds $3-5 \mu \mathrm{m},{ }^{19)}$ and the thickness for joints between iron and titanium is $4-6 \mu \mathrm{m} .{ }^{19}$ The strength of the steel wire/aluminium composite decreases rapidly with the increase in the thickness of layer more than $6 \mu \mathrm{m} .{ }^{20)}$ In the present investigation, the strength of $\mathrm{FCD} / \mathrm{Ti}$ joints was increased with bonding temperature and the thickness of the $\mathrm{TiC}$ layer in these joints, increasing with bonding temperature, was less than $3 \mu \mathrm{m}$. Therefore, the critical thickness of TiG layer in FCD/Ti joints may be regarded as more than $3 \mu \mathrm{m}$.

As shown in Figs. 7, 10, 11 and 13, remarkable changes in both tensile strength and microstructure of ULC/Ti and S20C/Ti joints were observed at the bonding temperature of about $900^{\circ} \mathrm{C}$. This bonding temperature is approximately equal to the temperature $T_{t r}$ of $\alpha \rightleftarrows \beta$ transformation of $\mathrm{Ti}\left(883^{\circ} \mathrm{C}\right.$ ), suggesting that the transformation has a great influence on the formation and growth of intermetallic compounds at the bond interface. That is, for ULG/Ti and S20C/Ti joints, the thickness of TiFe and $\mathrm{TiFe}_{2}$ layers was increased rapidly with bonding temperature above $T_{t r}$, while they could not be observed below $\mathcal{T}_{\iota r}$. Owing to this increase in the thickness of TiFe and $\mathrm{TiFe}_{2}$ layers, the strength of ULC/Ti joints was not increased with the rise in bonding temperature above $T_{t r}$, and that of $\mathrm{S} 20 \mathrm{C} / \mathrm{Ti}$ joints was de- 
creased.

\section{Conclusions}

Spheroidal graphite cast iron (FGD), low carbon steel with very low carbon content (ULG) and mild steel (S20C) have been diffusion-bonded to titanium, and the effects of carbon content on the microstructure and tensile strength of joint have been systematically investigated. Results obtained are summalized as follows:

(1) In the $\mathrm{FGD} / \mathrm{Ti}$ joint, an interlayer of $\mathrm{TiC}$ was formed at the bond interface. The intermetallic compounds $\mathrm{TiFe}$ or $\mathrm{TiFe}_{2}$, however, were not formed, since $\mathrm{TiC}$ was thermodynamically more stable than the intermetallic compounds and the interlayer of $\mathrm{TiC}$ acted as a barrier against the interdiffusion of $\mathrm{Fe}$ and $\mathrm{Ti}$ across the bond interface. The joint strength increased with bonding temperature; i.e., no decrease in the joint strength due to the growth of the $\mathrm{TiC}$ interlayer was observed.

(2) In the ULG/Ti joint, an intermetallic compound layer consisting of $\mathrm{TiFe}_{2}$ and $\mathrm{TiFe}$ was formed at the bond interface, while TiG could not be found. The bond strength increased with bonding temperature up to $900^{\circ} \mathrm{C}$, but became almost constant above $900^{\circ} \mathrm{C}$. This result suggests that the growth of the interlayer consisting of $\mathrm{TiFe}$ and $\mathrm{TiFe}_{2}$ suppressed the increase in the joint strength at bonding temperatures above $900^{\circ} \mathrm{C}$.

(3) At the bond interface of the S20G/Ti joint, a discontinuous interlayer of $\mathrm{TiC}$ was formed at bonding temperatures below $900^{\circ} \mathrm{C}$. At bonding temperatures above $900^{\circ} \mathrm{C}$, the bond interface consisted of the places where the interlayer of $\mathrm{TiC}$ was formed and where an interlayer of $\mathrm{TiFe}$ and $\mathrm{TiFe}_{2}$ was formed. The tensile strength of the S20G/Ti joint increased with bonding temperature below $900^{\circ} \mathrm{C}$, but above $900^{\circ} \mathrm{C}$ decreased with the rise in bonding temperature. These results suggest that the $\mathrm{TiFe}$ and $\mathrm{TiFe}_{2}$ interlayer coexisting with the $\mathrm{TiG}$ interlayer had more detrimental effects on the bond strength than those formed individually.

\section{REFERENCES}

1) T. Shiota, J. Satake and H. Nakagawa: Met. Technol. (Jpn.), 54 (1984), 25.

2) T. Ikemi, A. Yoshizawa and Y. Shindo: Pressure Enginnering, 19 (1981), 281.

3) A. Kubota, H. Ueda, T. Nakamura and H. Yoshinaga: Pressure Engineering, 19 (1981), 294.

4) K. Sakai, S. Ishioka, T. Izumi and I. Kawauchi: Pressure Engineering, 19 (1981), 305.

5) K. Tamaki, S. Nakano, N. Nishiyama, K. Hirose and A. Kamada: Pressure Engineering, 19 (1981), 313.

6) T. Okumura, Y. Nakai, K. Motoda and K. Kobayashi: Pressure Engineering, 19 (1981), 319.

7) T. Ohamae, Y. Hukaya and S. Inoue: Pressur Engineering, 19 (1981), 328.

8) M. Shimazaki, H. Kaga, Y. Baba, S. Nakajima and E. Maeda: Tetsu-to-Hagané, 71 (1985), S1645.

9) R. Yanagimoto, M. Shimazaki, H. Kaga, S. Nakajima and E. Maeda: Tetsu-to-Hagané, 71 (1985), S1646.

10) S. Yoshihara, T. Kawanami and K. Suzuki: Tetsu-toHagané, 72 (1986), 671.

11) Y. Arata, K. Terai, S. Matsuda, H. Nagai and T. Yamada: Trans. Jpn. Weld. Soc., 4 (1973), 96.

12) T. Enjo and K. Ikeuchi: Bull. Jpn. Inst. Met., 21 (1982), 959.

13) O. Ohashi: Tetsu-to-Hagané, 72 (1986), 373.

14) M. Hansen: Constitution of Binary Alloys, McGraw-Hill, New York, (1985), 723.

15) N. F. Kazakov: Diffusion Bonding of Materials, Pergamon Press, Oxford, (1985), 34.

16) I. Barin and O. Knache: Thermochemical Properties of Inorganic Substances, Springer-Verlag, Berlin, (1973), 116, $275,749,790$.

17) I. Barin, O. Knache and O. Kubaschewski: Thermochemical Properties of Inorganic Substances, Springer-Verlag, Berlin, (1977), Suppl, 257.

18) S. Yamaguchi and Y. Umakoshi: Intermetallic Compound (Kinzokukan Kagobutsu), Nikkan Kogyo Shinbunsha, Tokyo, (1984), 12.

19) G. K. Kharchenko: Auto. Weld. USSR, 22 (1969), No. 4, 31.

20) E. Friedrich, W. Pompe and I. M. Kopjov: J. Mater. Sci., 9 (1974), 1911. 